\title{
Personality Traits as Design Impetus for Learning Support
}

\author{
Christian Stary, Dominik Wachholder \\ Department of Business Information Systems \\ Johannes Kepler University Linz, Austria \\ Christian.Stary | Dominik.Wachholder@jku.at
}

\begin{abstract}
Digital learning support systems increasingly become common in educational and organizational settings. Taking into account personality and learning style for designing these systems is a further step towards user-centeredness, as both likely influence learning achievements, and thus, individual and organizational performance. This paper explores recent empirical inputs from learning science with respect to learner's disposition to inform design spaces for learning support systems. We structure these inputs and derive requirements for operational design.
\end{abstract}

\section{CCS Concepts}

- Applied computing Education • Human-centered computing $\sim$ HCI design and evaluation methods

\section{Keywords}

Learning Support, Personality, User-Centered Design.

\section{INTRODUCTION}

Besides technology, learner-centeredness has become a design issue in e-Learning. Thereby, learning support means enabling a high degree of autonomy for learners, and triggering learner activities rather than featuring passive consumption of prefabricated content [18]. Creation of knowledge, interaction with other stakeholders, and participation in organizing the learning process influence the acceptance of learning support systems also in organizational settings [3]. Personality and learning styles play significant roles in influencing performance achievements [15]. As they have been considered for design recently [2], our objective is to study how development activities of learning support systems correlate to personality factors. In the following, we derive some design requirements from existing findings and discuss exemplary features for implementation.

\section{THE BIG FIVE AS FRAME OF REFERENCE}

According to [9], virtually all personality measures can be described by (i) surgency or extraversion, (ii) agreeableness, (iii) conscientiousness or dependability, (iv) emotional stability (versus neuroticism) and (v) culture, intellect or openness. Acknowledged as the 'default model of personality structure' [16] due to its robustness and parsimoniousness, it enables exploring relationships between personality and education-relevant behaviors [15]:

Permission to make digital or hard copies of part or all of this work for personal or classroom use is granted without fee provided that copies are not made or distributed for profit or commercial advantage and that copies bear this notice and the full citation on the first page. Copyrights for thirdparty components of this work must be honored.

Copyright is held by the owner/author(s).

ECCE '16, September 05-08, 2016, Nottingham, United Kingdom

ACM 978-1-4503-4244-5/16/09.

http://dx.doi.org/10.1145/2970930.2970934

(C) (1) (-)

This work is licensed under a Creative Commons AttributionNonCommercial-ShareAlike International 4.0 License.
- Extraversion becomes evident through some higher degree of sociability, assertiveness, and talkativeness.

- Agreeableness is demonstrated by being helpful, cooperative, and sympathetic towards others.

- Conscientiousness is manifested through being disciplined, organized, and achievement-oriented.

- Emotional stability brings into play impulse control, and anxiety.

- Openness is reflected in a strong intellectual curiosity and a preference for novelty and variety.

Grouping these behaviors into a cognitive, social, and emotional dimension [14], we can identify design requirements (DR) for user-centered learning support, namely, a general one, DR1, and focused ones (DR2-6). For the latter we detail the evidence before subsuming them.

DR1: Learning support requires the provision of a social setting that fosters (i) social development of individuals, i.e. some form of process support in learning with respect to (a) extraversion's varying degrees of sociability, and (b) allowing (contextual) cooperation supporting agreeableness, and (ii) structural support for content generation and sharing to facilitate conscientiousness.

[13] studied the relationship between Internet usage and the Big Five. They could identify for total Internet usage a negative relation to three of the Big Five traits, namely extraversion, conscientiousness, and agreeableness. The same holds for another, narrow trait, namely work drive. The latter added significantly to extraversion and conscientiousness with respect to Internet usage. The Internet usage links the relationship to the personality of the learner, which could be measured and fed back to the learner before taking a course, thus, informing students as to how well these courses might warrant their investment of time and money [11].

[17] investigated the relationship between Big Five personality traits, online learning motivation and satisfaction in a digital English learning environment. According to their findings, personality traits correlate with online satisfaction. Extraversion and conscientiousness were the two important traits among the Big Five in predicting motivation and satisfaction. Motivation was a strong predictor of satisfaction. Five constructs of motivation, including escape, social contact, desire to learn, self-development and academic progress, were significantly related to satisfaction.

DR2: Learning support requires the provision of a social setting that allows control of emotions and developing emotional identity driving learning processes (emotional stability).

[5] have identified several (co-)relations of the personality trait factors with learning styles:

- Extraversion correlates positively with the meaning-, reproduction-, and application-directed learning style.

- Conscientiousness is associated positively with the meaning, reproduction-, and application-directed learning style, and negatively with the undirected learning style. 
- Openness correlates positively with the meaning- and application-directed learning style, and negatively with the undirected learning style.

- Neuroticism correlates positively with the undirected learning style and negatively with the meaning- and reproduction-directed learning style.

- Agreeableness is associated positively with the reproduction- and application-directed learning style.

[1] showed that two of the Big Five, namely conscientiousness and agreeableness, were positively related to the learning styles synthesis analysis, methodical study, fact retention, and elaborative processing, whereas neuroticism was negatively related with all four learning styles. Extraversion and openness were positively related to elaborative processing. According to their study, both, personality traits and learning styles contribute to academic performance. The relationship between openness and Grade Point Average (GPA) was mediated by reflective learning styles (synthesis-analysis and elaborative processing). These latter results suggest that being intellectually curious enhances academic performance when learners combine this scholarly interest with thoughtful information processing. [7] identified a positive link between openness to experience and deep learning, whereas openness is linked negatively to surface learning.

[10] found a significant relationship of conscientiousness to successful academic achievements. [1] suggested a moderating role of self-efficacy, as their findings revealed a positive indirect effect of neuroticism on academic performance. Moreover, this study showed that conscientiousness positively affected academic performance indirectly through academic motivation, but also that it is a condition for the indirect impact of extraversion, neuroticism, and conscientiousness.

DR3: Learning support design should reference to learning styles, in particular (i) directed learning (cf. DR1-ii), and (ii) exploration and reflection for deep learning, as both encounter conscientiousness, increasing self-efficacy through successfully achieving learning objectives.

[4] examined the relationship between the Big Five model of personality and the use of self-regulated learning strategies. Their correlation analysis indicates an overlap between the Big Five personality factors and self-regulatory learning strategies. In this study, effort regulation mediated the effects of conscientiousness and agreeableness.

With respect to performance, [8] found prior educational attainment and conscientiousness related to learning strategies. [15] went further to academic achievements, taking into account a model of effective information processing. It takes into account depth of processing, and encouragement of learners. Depth of processing has clear implications for personality, especially openness.

"Of the four learning styles,

- Synthesis-analysis refers to processing information, forming categories, and organizing them into hierarchies.

- Elaborative processing refers to connecting and applying new ideas to existing knowledge and to the learner's personal experiences.

- Methodical study consists of what is traditionally emphasized in most academic environments, such as being careful and methodical while completing all assignments on time.
- Fact retention involves processing information so that the main ideas are memorized with the goal of doing well on tests rather than understanding the meaning of what is being learned.

Deep processors are more likely to use appropriate study methods, draw conclusions effectively, and have a stronger internal locus of control. Deep processors are also more likely to be conscientiousness, intellectually curious, extraverted, and emotionally stable. Finally, students who prefer a structured learning environment and intuitive processing are prone to anxiety and worry, whereas those preferring an activist and pragmatist style are more extraverted. Thus, learning styles and personality traits appear to be intricately connected, although how they jointly influence academic achievement is unclear." (p. 473)

DR4: Learning support design should enable if not trigger deep learning experience (see also DR3).

[6] could show that virtual environments require special attention with respect to learner engagement. They examined the impacts of the instructional environment (classroom vs. Web-based) and personality differences on social participation among university students. Face-to-face instruction seems to enhance students' active participation whereas Web-based learning support appears to inhibit it. Influence factors requiring special attention when designing e-Learning systems were extroversion, openness to new experiences, and emotional stability, as the participants experienced these factors only positively in face-to-face settings (compared to virtual settings). The results point to the psychological impact of the two instructional environments, and suggest viewing social participation as a result of educational context. Thereby individual differences seem to play secondary role.

DR5: In virtual settings, learner socialization needs to be an explicit design issue, in particular when promoting active participation of learners.

When [12] examined learners' personality traits and their effects on learning preferences they developed a design guideline on the learning style: The structure of instructional design is related to the level of extraversion. Adaptable e-learning systems could provide optimization processes or mechanisms for each user's learning style and characteristics. They would allow for personalized learning experiences. Their study showed a significant difference in the learning performance of participants who were identified as introverts vs. those who were identified as being extroverts. The authors came up with design guidelines for organizing content, as they could reinforce the above mentioned correlation between personality type and learning experience.

DR6: The design of learning support should feature levels of extraversion as they allow different forms of learner engagement. With respect to individual learning processes and organizational learning steps respectively, the visibility of engagement (e.g., interaction, annotation, etc.) needs to be configurable in terms of access permissions ranging from complete transparency to private.

Using the Big Five as frame of reference, the above proposed design requirements (DR1 - DR6) were formulated referring to the different dimensions of learning (cognitive, social, and emotional). DR1 stresses the importance of the cognitive and social dimension of learning, whereas DR2 - DR6 focus on a specific dimension (cognitive: DR3, DR4, social: DR5, DR6, emotional: DR2) addressing particular design aspects. 


\section{EXEMPLARY DESIGN IMPLEMENTATIONS}

Based on the design requirements, we have developed the Webbased learning support system UeberLearn.

\subsection{Providing a Structured Point of Entry}

As the point of entry in UeberLearn a dashboard is presented revealing latest activities in a learning community of a learner on a separate part of the screen, an infoboard, and a register card for all the projects of a learner. The infoboard complements the learning support with organizational information, such as current topics of discourse or upcoming meetings for sharing knowledge. Projects contain all content and social interaction capabilities provided for learners ("project" and "menu" in Figure 1). In the case of study modules, face-to-face meeting dates and project deadlines can be displayed in the infoboard section. The projects space contains (i) technical content, (ii) assignments and further material, and (iii) gen-erated notes and interactions of the participants referencing a certain project. These projects are categorized according to the modules to be taken in the course of study (cf. DR 1).

Both the dashboard and the projects part provide basic orientation from an organizational and content perspective. It can be considered as minimal aid to structure learning processes. In addition, the educator tagged each project content element according to its didactic meaning, such as motivation, definition, example, explanation, or background information (cf. DR3, DR 4).

\subsection{Featuring Notes as Central Medium of Interaction}

Once a project has been selected (Figure 1) the central workspace for learning support is displayed - a note taking board. The board keeps all created notes and is initialized for each project and registered learner. It is always displayed according to the selected project for each user. Hence, the workspace structure for facilitators and learners has been designed identical. So far, the privilege to make notes part of module or course content has been restricted to facilitators, in order to assure the correctness of content provided for all in addition to the already provided content and materials for download.

Rather than listing assignments or pre-fabricated content elements, initially all entered inputs of the learner (comments, notes, questions) are listed. A bar indicates which part of the learning support systems is activated (cf. "menu" in Figure 1). In this way learners can immediately join social interactions. Each learner is also informed on recent activities from others as the workspace in the center reveals individual notes. Notes remain private or are shared among selected members in the context of projects (cf. DR5, "interactions" and "participants" in Figure 1). Although notes can contain any type of content type, including links and multimedia, their original context remain accessible, thus, triggering context-sensitive discussions rather than context-less threads.

Note taking in the context of a certain project provides minimal structural guidance and triggers social engagement. As notes can be linked to any content, deep learning processes driven individually can be triggered (cf. DR3, DR4).

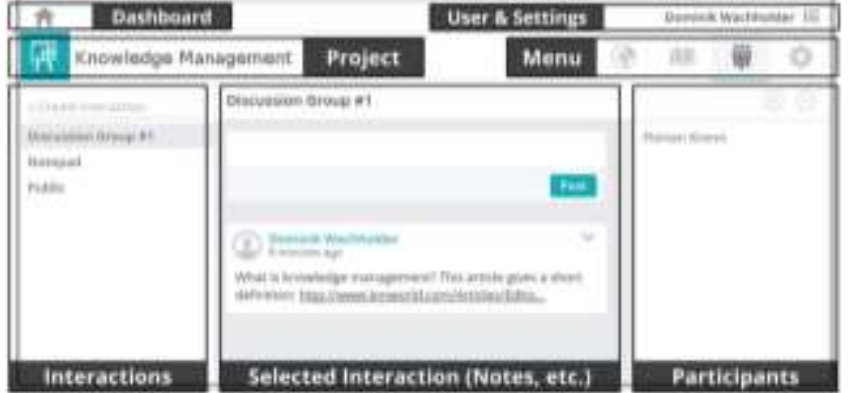

Figure 1. The project's interaction view in UeberLearn.

Figure 1 exemplarily shows the prototypical design and implementation of the project's interaction view in UeberLearn. Besides common navigational elements, such as the menu, the user \& settings area, and the linking to the dashboard, learners can customize interactions (DR2, DR6), each of which is configurable to personal needs (e.g., privacy).

\section{CONCLUSION}

In this paper, we have tried to bridge the gap between learningrelevant personality traits and learner-centered design of learning support systems. Rather than measuring behavior of users when working with this kind of system, we tried to motivate the respective design of learning support systems. As a result, learning support systems need to provide primarily a social setting. This setting should trigger individual learning steps, which in turn trigger community developments through adequate content management and process support. The self-control of users is crucial for supporting various levels of extraversion and conscientiousness. The emotional dimension of learning still needs to be studied in further research to identify concrete design requirements. In these studies, existing measurements need to be applied, in order to reveal the effectiveness of features designed according to the proposed requirements.

\section{REFERENCES}

[1] Tim De Feyter, Ralf Caers, Claudia Vigna, and Dries Berings. Unraveling the impact of the Big Five personality traits on academic performance: The moderating and mediating effects of self-efficacy and academic motivation. Learning and Individual Differences 22, 4 (2012): 439-448.

[2] Roelof A.J. De Vries, Khiet P. Truong, and Vanessa Evers. Crowd-Designed Motivation: Combining Personality and the Transtheoretical Model. In Persuasive Technology (2016), 41-52. Springer International Publishing.

[3] Bo Cheng, Minhong Wang, Jürgen Moormann, Bolanle A. Olaniran, and Nian-Shing Chen: The effects of organizational learning environment factors on e-learning acceptance. Computers \& Education (2012) 58, 3: 885-899.

[4] Temi Bidjerano and David Yun Dai. The relationship between the big-five model of personality and self-regulated learning strategies. Learning and Individual Differences 17, 1 (2007): 69-81.

[5] Vittorio V. Busato, Frans J. Prins, Jan J. Elshout, and Christiaan Hamaker. The relation between learning styles, the Big Five personality traits and achievement motivation in higher education. Personality and individual differences 26, 1 (1998): 129-140.

[6] Avner Caspi, Eran Chajut, Kelly Saporta, and Ruth BeythMarom. The influence of personality on social participation 
in learning environments. Learning and Individual Differences 16, 2 (2006): 129-144.

[7] Tomas Chamorro-Premuzic and Adrian Furnham. Mainly Openness: The relationship between the Big Five personality traits and learning approaches. Learning \& Indiv. Differences 19, 4 (2009): 524-529.

[8] Angus Duff, Elizabeth Boyle, and Karen Dunleavy, John Ferguson. The relationship between personality, approach to learning and academic performance. Personality and Individual Differences 36, 8 (2004): 1907-1920.

[9] Lewis R. Goldberg, An alternative description of personality: the big-five factor structure. Journal of personality \& social psychology 59, 6 (1990): 1216-1229.

[10] Soraya Hakimi, Elaheh Hejazi, and Masoud Gholamali Lavasani. The Relationships Between Personality Traits and Students' Academic Achievement. Procedia - Social and Behavioral Sciences 29 (2011): 836-845.

[11] Eyong B. Kim and Marc J. Schniederjans. The role of personality in web-based distance education courses Communications of the ACM 47, 3 (2004): 95-98.

[12] Jieun Kim, Ahreum Lee, and Hokyoung Ryu. Personality and its effects on learning performance: Design guidelines for an adaptive e-learning system based on a user model. International Journal of Industrial Ergonomics 43, 5 (2013): 450-461.
Richard N. Landers and John W. Lounsbury. An investigation of Big Five and narrow personality traits in relation to Internet usage, Computers in Human Behavior 22, 2 (2006): 283-293.

[13] Colin Lankshear and Michele Knobel. New Literacies: Everyday Practices and Social Learning. McGraw-Hill Education (UK) (2011).

[14] Meera Komarraju, Steven J. Karau, Ronald R. Schmeck, and Alen Avdic. The Big Five personality traits, learning styles, and academic achievement. Personality and Individual Differences 51, 4 (2011): 472-477.

[15] Robert R. McCrae and Costa Jr., Paul T. Introduction to the empirical and theoretical status of the five-factor model of personality traits. In Widiger, Thomas A. (Ed); Costa, Paul T., Jr. (Ed), (2013). Personality disorders and the five-factor model of personality (3rd ed.), American Psychological Association: 15-27.

[16] Hsiu-Feng Shih, Shu-Hui Eileen Chen, Shu-Chu Chen, and Shyh-Chyi Wey. The Relationship among Tertiary Level EFL Students' Personality, Online Learning Motivation and Online Learning Satisfaction. Procedia-Social and Behavioral Sciences 103 (2013): 1152-1160.

[17] Weimer Maryellen. Learner-centered teaching: Five key changes to practice. San-Francisco: Josey-Bass (2009). 